CASE REVIEW 3

POR DESCONOCER EL DERECHO MORAL

DEL FOTÓGRAFO MARCUS IGNO RUDOLF

LOERBROCKS LA DIRECCIÓN NACIONAL DE

DERECHO DE AUTOR CONDENÓ AL COLEGIO

MONTESSORI LIMITADA DE CARTAGENA

TATIANA ANDREA TRIANA URIBE*

La Dirección Nacional de Derecho de Autor (en adelante, DNDA), a través de la Subdirección de Asuntos Jurisdiccionales, emitió fallo el 1. ${ }^{\circ}$ de febrero de 2017, en el proceso civil por derechos de autor interpuesto por el señor Marcus Igno Rudolf Loerbroks contra el Colegio Montessori Limitada de la ciudad de Cartagena, por haber publicado sin autorización una fotografía de su autoría en la página web de la institución educativa.

El señor Marcus Igno Rudolf Loerbroks (demandante) solicitó la protección de sus derechos morales a través de demanda radicada el 26 de agosto de 2015, reformada el 28 de junio de 2016, en razón de que el Colegio Montessori Limitada de la ciudad de Cartagena (demandado) publicó en su página web (www.colegiomentessori.edu.co) la fotografía identificada como DEMONTESSORI3101: MCs2353. JPG sin tener su autorización, vulnerando así sus derechos morales y debiendo en consecuencia resarcir los daños extrapatrimoniales ocasionados.

Por otra parte, el demandado expresó que no hay lugar a reconocer la existencia de vulneración alguna a los derechos de autor del demandante, puesto que él contaba con los derechos para realizar la publicación basado en la propuesta realizada por el propio demandante a la institución educativa, la cual consistía en "realizar un estudio fotográfico a la institución educativa y cruzar el valor del mismo con el valor de las pensiones no pagas de los hijos del señor Marcus Igno Rudolf Loerbroks", y dentro del estudio fotográfico realizado se encuentra la fotografía en controvesia. Con fundamento en dichas tratativas el demandado subió la fotografía en su página web.

Es preciso tener en cuenta que el 12 de marzo de 2014 la institución educativa envió comunicación suscrita por su representante legal al demandante manifestando que las fotos "no son aprobadas por la dirección general, por lo tanto no se pudo realizar el cruce de cuentas".

* Estudiante de Derecho y asistente de investigación del Departamento de Propiedad Intelectual de la Universidad Externado de Colombia, Bogotá, Colombia. Contacto: tatianatrianau@hotmail.com. DoI: https://doi.org/10.18601/16571959.n23.12 


\section{Problema jurídico}

En el caso en mención, el centro de la discusión recae en: primero, determinar si el accionante es sujeto de derechos morales, y segundo, establecer la eventual violación de los derechos morales en cabeza del señor Loerbroks después de llevarse a cabo la publicación de la fotografía en mención en la página web del Colegio Montessori.

\section{Hechos}

En agosto de 2009 el señor Marcus Igno Rudolf Loerbroks presentó una cotización de tomas fotográficas en digital de alta resolución a la institución educativa Colegio Montessori Limitada de la ciudad de Cartagena, la cual fue enviada nuevamente en octubre de 2011.

Durante el proceso de negociación se pactó de forma verbal la ejecución del trabajo fotográfico el día 14 de mayo de 2012 en las instalaciones del Colegio; se acordó que el valor del estudio fotográfico se debía compensar con el valor de las matrículas que adeudadas por el demandante, de sus hijos menores estudiantes del Colegio.

En agosto del mismo año, luego de ser entregado el estudio fotográfico, la institución educativa comenzó a impedir el ingreso de los hijos del demandado al plantel por no haber cancelado la matrícula; fue en ese momento que el demandante se dio cuenta de que el Colegio estaba incumpliendo con lo acordado. Días después el demandado, a través de su directora financiera y administrativa, manifestó "que no aprobaría la compra de la producción fotográfica que ya se había entregado, y que procedería a la devolución del material entregado". A continuación el señor Loerbroks realizó varios requerimientos a la institución con el fin de obtener los DVD con el material entregado, dentro de los cuales se encontraba la imagen objeto de estudio identificada bajo la denominación: "DEMOMONTESSORI3101: MCS2353.JPG".

El Colegio procedió a modificar y publicar la imagen en cuestión en su página web (www.colegiomontessori.edu.co) sin contar con la autorización del autor de dicha obra y sin haber llevado a cabo el pago del estudio fotográfico realizado por el demandante.

\section{TRÁMITE}

Después que el señor Loerbroks solicitó al Colegio el retiro de la imagen de su página web sin obtener resultado positivo alguno, presentó queja ante la DNDA, la cual sugirió "celebrar audiencia de conciliación" con el fin de solucionar el conflicto; dicha audiencia fue declarada fallida porque no se llegó a un acuerdo entre las partes convocadas y por lo tanto se surtió el requisito de procedibilidad establecido en el artículo 621 de la Ley 1564 de 2012 (Código General del Proceso). 
Se continuó con el trámite de la demanda y el Colegio en calidad de demandado la contestó diciendo que "[e]l señor Loerbroks, contituyó una mora por el no pago de las pensiones de sus dos hijos que ascendieron a la suma de $\$ 1.100 .000$. oo" y, con el fin de sanear esta obligación, propuso la realización del estudio fotográfico para cruzar cuentas. La institución educativa justificó la utilización de la obra fotográfica en que ya se había llevado a cabo una negociación comercial y "la propuesta sería llevada ante el comité financiero, por ser atípica a la modalidad de pago. Posteriormente vía correo se le informa al señor Marcus Igno Rudolf Loerbroks, que estaban dispuestos a hacerlo y que escogerían las fotos que se requerirían en su oportunidad"; además, el Colegio también afirmó que "en ningún momento se desconoció la autoría de las fotografías, por el contrario en cada una de las formas de comunicación le ha reconocido tal derecho".

Finalmente, el 1. ${ }^{\circ}$ de febrero de 2017 se llevó a cabo la audiencia de instrucción y juzgamiento, en la cual el subdirector de asuntos jurisdiccionales de la DNDA dictó sentencia en primera instancia, declarando que el Colegio vulneró el derecho moral de mantener la obra inédita o divulgación del señor Loerbroks sobre la obra fotográfica de la referencia; que el demandado debía presentar excusas públicas por medio de una publicación en su página web reconociendo la autoría del señor Loerbroks sobre la obra fotográfica, y que además debía pagarle al demandante una suma de dinero por concepto de perjuicio extrapatrimonial.

\section{ANÁLISIS}

En primer lugar es preciso mencionar que en la legislación colombiana y a nivel internacional "derecho de autor" es la expresión que se utiliza para referirse a los derechos que obtienen los titulares de una creación intelectual, una obra, ya sea de carácter literario, científico o artístico; según lo establecido en el artículo 2 de la Ley 23 de 1982 sobre Derechos de Autor, estas comprenden "todas las creaciones del espíritu en el campo científico, literario y artístico, cualquiera que sea el modo o forma de expresión y cualquiera que sea su destinación"'.

1 Ley 23 de 1982, art. 2: "Los derechos de autor recaen sobre las obras científicas, literarias y artísticas, las cuales comprenden todas las creaciones del espíritu en el campo científico, literario y artístico, cualquiera que sea el modo o forma de expresión y cualquiera que sea su destinación, tales como: los libros, folletos y otros escritos; las conferencias, alocuciones, sermones y otras obras de la misma naturaleza; las obras dramáticas o dramático-musicales; las obras coreográficas y las pantomimas; las composiciones musicales con letra o sin ella; las obras cinematográficas, a las cuales se asimilan las obras expresadas por procedimiento análogo a la cinematografía, inclusive los videogramas; las obras de dibujo, pintura, arquitectura, escultura, grabado, litografía; las obras fotográficas, a las cuales se asimilan las expresadas por procedimiento análogo a la fotografía; las obras de arte aplicadas; las ilustraciones, mapas, planos, croquis y obras plásticas relativas a la geografía, a la topografía, a la arquitectura o a las ciencias y, en fin, toda producción del dominio científico, literario o artístico que pueda reproducirse, o definirse por cualquier forma de impresión o de reproducción, por fonografía, radiotelefonía o cualquier otro medio conocido o por conocer. Adiciona mediante la Ley 44 de 1993”. 
Es así como la DNDA explica que esta forma jurídica goza de una naturaleza especial de propiedad, lo que hace que se diferencie de la propiedad privada sobre bienes tangibles, ya que no recae sobre cosas corporales sino sobre la creación inmaterial, otorgando diferentes derechos y buscando así incentivar al autor por el empeño que hizo posible la existencia de la obra.

Así las cosas, el objeto de protección de los derechos morales en cabeza del autor es la obra, haciendo alusión al género de las fotografías dentro de la categoría denominada artística del listado no taxativo del artículo 2 de la Ley 23 de 1982 sobre Derechos de Autor y la Decisión Andina 351 de 1993 de la Comunidad Andina que reglamenta el Régimen Común sobre Derechos de Autor y Derechos Conexos.

Para la DNDA, es claro que la fotografía identificada es una creación artística, por lo que de esa autoria surgen en principio dos derechos: "derechos morales y derechos patrimoniales. Los derechos patrimoniales, incluida su titularidad, no son objeto de discusión en la presente causa [...] posible infracción de los derechos morales del demandante".

Se realizó un amplio análisis por parte de la DNDA para determinar los derechos morales vulnerados al señor Loerbroks. Es así como se reconoce una afectación sobre los derechos morales, los cuales están fuera del comercio y por lo tanto no son objeto de negociación, considerándose en Colombia perpetuos, inalienables e irrenunciables.

Diversa es la normatividad internacional ${ }^{2}$, en donde se reconcen y establecen los derechos morales de paternidad, integridad, divulgación, modificación y retracto, los cuales procedo a explicar de forma breve.

2 Convenio de Berna, art. 6 bis: "Derechos morales: 1. Derecho de reivindicar la paternidad de la obra; derecho de oponerse a algunas modificaciones de la obra y a otros atentados a la misma; 2. Después de la muerte del autor; 3. Medios procesales: “1) Independientemente de los derechos patrimoniales del autor, e incluso después de la cesión de estos derechos, el autor conservará el derecho de reivindicar la paternidad de la obra y de oponerse a cualquier deformación, mutilación u otra modificación de la misma o a cualquier atentado a la misma que cause perjuicio a su honor o a su reputación.

“2) Los derechos reconocidos al autor en virtud del párrafo 1) serán mantenidos después de su muerte, por lo menos hasta la extinción de sus derechos patrimoniales, y ejercidos por las personas o instituciones a las que la legislación nacional del país en que se reclame la protección reconozca derechos. Sin embargo, los países cuya legislación en vigor en el momento de la ratificación de la presente Acta o de la adhesión a la misma, no contenga disposiciones relativas a la protección después de la muerte del autor de todos los derechos reconocidos en virtud del párrafo 1) anterior, tienen la facultad de establecer que alguno o algunos de esos derechos no serán mantenidos después de la muerte del autor.

“3) Los medios procesales para la defensa de los derechos reconocidos en este artículo estarán regidos por la legislación del país en el que se reclame la protección”.

Decisión 351 de 1993 de la Comunidad Andina, que reglamenta el Régimen Común sobre Derechos de Autor y Derechos Conexos: "Artículo 11. El autor tiene el derecho inalienable, inembargable, imprescriptible e irrenunciable de: a) Conservar la obra inédita o divulgarla; b) Reivindicar la paternidad de la obra en cualquier momento; y, c) Oponerse a toda deformación, mutilación o modificación que atente contra el decoro de la obra o la reputación del autor. A la muerte del autor, el ejercicio de los derechos morales corresponderá a sus derechohabientes, por el plazo a que se refiere el Capítulo vi de la presente Decisión. Una vez extinguido el derecho patrimonial, el Estado u otras instituciones designadas, asumirán la defensa de la paternidad del autor y de la integridad 
1. El derecho moral de paternidad consiste en el reconocimiento que se hace al autor de la obra en la utilización que se haga de la misma, es decir que el autor en todo momento puede decidir si quiere reivindicar su condición de autor, creador de la obra o, por el contrario, si quiere aparecer como autor anónimo.

2. El derecho moral de integridad se refiere a la facultad que tiene el autor para immpedir que terceros no autorizados (personas sin el consentimiento expreso y previo del titular) puedan alterar, modificar, agregrar, introducir o enmendar la obra originalmente creada; además, si dichos actos causan perjuicio al nombre y reputación del autor, este puede demandar la reparación o indemnización por tales actos.

3. El derecho moral de divulgación es la facultad que otorga la ley al autor de una obra para decidir si la misma es comunicada al público o publicada.

4. El derecho moral de modificación es aquel que faculta al autor para que modifique su obra antes o después de su publicación.

5. El derecho moral de retracto permite que el autor pueda retirar la obra publicada, previa la indemnización de los perjuicios que con esta acción cause a terceros.

Nuestra Corte Constitucional también se ha pronunciado indicando al respecto que "los derechos morales de autor se consideran derechos de rango fundamental, en cuanto la facultad creadora del hombre, la posibilidad de expresar las ideas o sentimientos de forma particular, su capacidad de invención, su ingenio y en general todas las formas de manifestación del espíritu, son prerrogativas inherentes a la condición racional propia de la naturaleza humana y a la dimensión libre que de

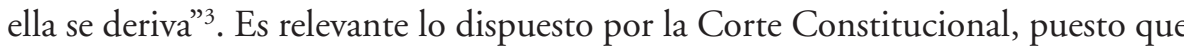
su intención es proteger los derechos de autores, actores, directores y dramaturgos, frente a sus derechos laborales y de seguridad social, y por lo tanto al decir que los derechos de autor son inalienables lo que nos quiere decir es que las implicaciones que estos tienen en la aplicación de los artículos 48 y 53 de la Constitución Política donde se manifiesta la "irrenunciabilidad a los beneficios mínimos establecidos en normas laborales", conviritiendo así el derecho a la seguridad social de los titulares en un derecho irrenunciable y diferenciado de la cesión y enajenación de los derechos patrimoniales.

De acuerdo a lo expuesto en las anteriores normas y sentencias, el caso en particular muestra cómo la acción llevada a cabo por la institución educativa fundamenta la violación del derecho moral radicado en cabeza del señor Loerbroks, acción consistente en la modificación y posterior publicación en la página web del Colegio de la imagen tomada por el demandante. 
El derecho moral de integridad consiste, según el literal c) del artículo 11 de la Decisión Andina 351 de 1993 de la Comunidad Andina, que reglamenta el Régimen Común sobre Derechos de Autor y Derechos Conexos, "en la facultad del autor para oponerse a toda deformación, mutilación o modificación que atente contra el decoro de la obra o la reputación del autor". No obstante, no se probó que las modificaciones realizadas a la fotografía atentaran contra el derecho de la obra o la reputación del autor, elemento este necesario al que debe adecuarse el supuesto de hecho ${ }^{4}$, puesto que en Colombia para llevar a cabo la indemnización a una violación al derecho de autor se siguen los criterios de la responsabilidad civil, los cuales son: i. La acreditación de la infracción, ii. La existencia de un daño, iii. La evaluación de la conducta y iv. La existencia de un nexo causal entre el daño y la conducta. Una vez identificados estos criterios se puede derterminar si se realiza un reproche para sustentar la carga de remediar el perjuicio causado. Así las cosas, la infracción a un derecho moral supone, en primer lugar, un daño extrapatrimonial, y en segundo lugar, daños materiales cuando la infracción recaiga sobre el patrimonio del autor. Una vez acreditados los elementos de la responsabilidad civil extracontractual, el juez es el encargado de tasar el valor de los perjuicios, ya que la cuantificación del daño debe hacerse "de forma equilibrada, fundada en motivos probados, teniendo en cuenta tanto la extensión del golpe emocional producido por el hecho dañino, como las circunstancias particulares que lo rodearon, las cuales son las que distinguen cada caso de otros similares, así como también debe tenerse en cuenta la afectación de la persona, el grado de fuerza del dolor infligido y la facultad de cada sujeto de soportar dicho dolor"s.

En cuanto al derecho moral de divulgación, es preciso aclarar que si bien entre el Colegio y el señor Loerbroks existieron trativas negociales, para realizar la compensación de una deuda con el pago del estudio fotográfico, la misma institución educativa no aprobó las fotografías ni realizó el cruce de cuentas; así las cosas, el Colegio para publicar la fotografía en la página web debía contar con la autorización del autor de la misma.

Es claro para el juez que se presenta la violación por parte del demandado del derecho moral de divulgación que detenta el autor sobre la obra fotográfica. Pero veamos más a fondo: el daño, en derecho civil, significa el detrimento o perjuicio que una persona sufre y que afecta a sus bienes, derechos o intereses; mientras que en el derecho de autor, los intereses legalmente protegidos son las obras, a través de los derechos patrimoniales y morales, por lo cual se ve materializado el

4 Tribunal de Justicia de la Comunidad Andina, pronunciamiento 59-IP-2014: "El autor tiene derecho a oponerse cuando se trate de una deformación, una mutilación o una modificación, siempre que se cumpla con el requisito adicional de atentar contra el honor, el respeto del autor y la honestidad de su obra”.

5 Dirección Nacional de Derechos de Autor, Subdirección de Asuntos Jurisdiccionales. Sentencia de 6 de febrero de 2017, Marcus Igno Rudolf Loerbroks vs. Colegio Montessori Limitada de la ciudad de Cartagena, p. 13. 
daño cuando se infringe alguno de estos derechos, ya que le impide al titular el ejercicio del mismo.

Entonces, ¿qué es el derecho moral de mantener la obra inédita o divulgación? De acuerdo con lo establecido en el literal a) del artículo 11 de la Decisión Andina 351 de 1993 de la Comunidad Andina, que reglamenta el Régimen Común sobre Derechos de Autor y Derechos Conexos, el autor tiene dereho a conservar su obra inédita o divulgarla. La obra es inédita cuando no ha sido dada a conocer al público, como lo estipula el artículo 8 de la Ley 23 de $1982^{[6]}$, sobre Derechos de Autor; mientras que divulgar es hacer accesible la obra al público por cualquier medio o procedimiento, según el artículo 3 de la Decisión Andina 351 de $1993^{[7]}$ que reglamenta el Régimen Común sobre Derechos de Autor y Derechos Conexos. Luego, el derecho de divulgación es la facultad personalísima que ostenta el autor de decir si da o no a conocer su obra y en qué forma; ya que solo él puede tomar esta decisón, y es por esto que la infracción se configura cuando un tercero ejerce la facultad personalísima del autor sin estar autorizado para hacerlo.

En un caso similar, ocurrido el 16 de agosto de 2016, la DNDA condenó al centro comercial San Diego, en la ciudad de Medellín, a pagar una suma de 100 s.m.l.m.v. a favor del artista Gabriel Antonio Calle con fundamento en el desconocimiento del derecho moral de la integridad del artista. El tema central de este fallo fue la vulneración de los derechos de autor del artista que por encargo del centro comercial San Diego, en el año 2006, pintó un mural denominado "Líder" en el costado occidental del mismo con el fin de embellecerlo, mural que, debido al deterioro producido por el paso del tiempo, el centro comercial decidió borrar, esto en el segundo semestre de 2013. Al respecto cabe mencionar que en el caso del muralismo cobra especial relevancia el hecho de que habitualmente el artista no es dueño de las paredes donde elabora sus obras ${ }^{8}$.

Con los dos fallos de la DNDA acá reseñados comenzamos a ver una muy importante línea jurisprudencial en concordancia con la sentencia C-155 de 1998 de la Corte Constitucional, ya que de forma sobresaliente se ve la inminente proteción y atención que debe otorgarse a los titulares de los derechos de autor, en especial cuando se habla de los derechos morales que gozan los titulares de las obras.

6 Ley 23 de 1982, art. 8: "literal g). Obra inédita: aquella que no haya sido dada a conocer al público”.

7 Decisión 351 de 1993 de la Comunidad Andina, art. 3: "A los efectos de esta decisión se entiende por: [...] Divulgación: Hacer accesible la obra al público por cualquier medio o procedimiento".

8 Véase Daniela Molano Lozano, en: http://propintel.uexternado.edu.co/batalla-ganadapara-los-derechos-morales-de-los-artistas-decision-hito-en-colombia/ 